\section{Ready. Set. Move! Sports Medicine Australia advocates movement as medicine for all!}

\author{
Michelle Bergeron, ${ }^{\oplus 1,2}$ Liam Richard West, $^{\oplus 3}$ Emmanuel Stamatakis $^{\oplus 4}$
}

\section{AGEING, DEATH AND TAXES ARE CERTAIN: CAN PHYSICAL ACTIVITY (PA) HELP US AGE MORE GRACEFULLY?}

While we cannot help you with taxes, we are certain that this issue is packed with important new evidence on various less explored aspects of PA that can minimise ageing-related detriments in health. Regular PA improves health outcomes and 'adds years to life and life to years'. Historically, moderate intensity exercise has been recommended-in at least 10 continuous minute sessions-to see any real improvement in health and fitness. Previous research has struggled to capture bouts of lighter intensity $\mathrm{PA}$, and this has made it difficult to determine its health benefits. Dr Barbara's Jefferis and colleagues' (See page 1013) study is among the first to use accelerometers to examine the association of PA of all durations and intensities to investigate all-cause mortality in British men aged 71-92 years. In older age, any intensity or duration of PA was beneficial; this should help motivate these populations to get active. The Jefferis study will be used in forthcoming PA guideline updates, under development by the UK's chief medical officers and by the WHO. It is a powerful piece of work that is definitely worth a read! Professors Andreas Holtermann and Emmanuel Stamatakis (See page 991) put forward a slightly different perspective by arguing that the context where PA is done, as well as how we measure it, is at least as important as the total amount of PA. Could the largely 'for fun' context of leisure time PA explain its superior health effects over the non-negotiable occupational PA, which has unclear health effects? Do you encourage your patients who already have active populations to engage in regular fun $\mathrm{PA}$ ?

\footnotetext{
${ }^{1}$ Melbourne Physiotherapy, Pilates and Fitness Group, St Kilda, Victoria, Australia

${ }^{2}$ Artistic Health Team, Australian Ballet, Southbank, Victoria, Australia

${ }^{3}$ Olympic Park Sports Medicine Center, Melbourne, Victoria, Australia

${ }^{4}$ School of Public Health, University of Sydney, Sydney, New South Wales, Australia
}

Correspondence to Michelle Bergeron, Melbourne Physiotherapy, Pilates and Fitness Group, St Kilda, Victoria 3182, Australia; physio@michellebergeron.ca
Balance is increasingly emphasised in PA guidelines as a measure to prevent falls in older people, but practitioners seek specific tips. Dr Melanie Farlie's meta-analysis (See page 996) found no clear evidence that specific prescription of frequency, time or duration of balance promoting exercise is better than non-specific guidelines among older adults. This continues to press the point of Dr Jefferis' accelerometry study: just move more! Rebecca Atchison's (See page 1036) Bright Sport editorial describes the Active for Health Rotherham programme, which addresses activity levels in at-risk populations, such as patients with cancer, chronic obstructive pulmonary disease or heart disease. The key to its success is the major role of the community exercise providers, a worthy lesson for similar initiatives.

\section{PA IS GREAT FOR HEALTH: DOES IT ALSO PREVENT SPORTS INJURIES?}

Lighter intensity PA of any duration decreases mortality in middle to older age, but younger athletes tend to be more concerned with injuries rather than long-term mortality risks, especially female athletes, as Alicia Montalvo and colleagues (See page 1003) highlight in this issue. The authors show that the risk of anterior cruciate ligament (ACL) injury in a season is much higher among women, and they share specific injury prevention strategies with sports medicine clinicians. Along with ACL injury prevention, concussion is a top sports medicine priority, especially among rugby union players whose tackling practices often risk head-to-head collisions, with the tackler being the victim 70\% of the time. Mathew Cross and colleagues (See page 1021) undertook an innovative video analysis study and prove that the tackler's speed and acceleration could be modified to prevent the head-to-head contact that can cause concussion. Concussion prevention within rugby union is also important for grassroots enthusiasts who, according to Dr Doug King and colleagues (See page 1026), have doubled their rugby union-related insurance claims in just 5 years between 2012 and 2016 in New Zealand. From 5 years of Accident Compensation Corporation data, the authors report that rugby union recorded the most moderate-to-serious and serious injury (of any kind) entitlement claims and

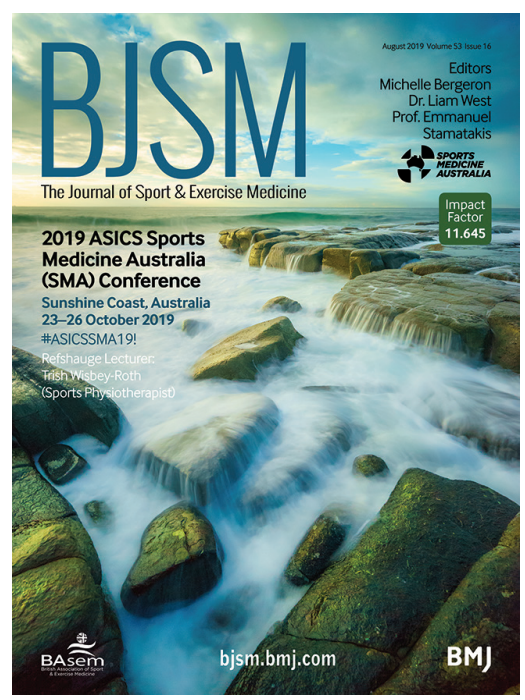

costs in New Zealand. Do physicians need to start prescribing tackling lessons to all New Zealanders? Ensuring that sports participation is safer ultimately leads to increased, uninterrupted by injury, regular PA levels, the overarching theme of this Sports Medicine Australia (SMA)-led issue of British Journal of Sports Medicine!

\section{CONFERENCE INVITATION}

PA is a top priority for us here at SMA, which is why the 2019 ASICS SMA conference at Twin Waters, Sunshine Coast, Australia, will touch on the same theme (figure 1). Keynote speakers include Professor Ewa Roos, driver of the worldwide success GLA:D programme for people living with arthritis; Dr Rasmus Neilsen of RUNSAFE, who looks at barriers to adherence in running; as well as Australia's own Professor Maria Fiatarone Singh, who looks at how resistance training counteracts the catabolism of ageing-just a tiny tiny sample of a wonderful programyou're sure to learn a great deal! SMA meetings are unapologetically social and friendly, and Queesland is idea in October. We can't wait to see you there from 23 to 26 October 2019 !

Contributors Equal contributions by all 3 authors on this Warm-up submission.

Competing interests None declared.

Patient consent for publication Not required.

Provenance and peer review Commissioned; internally peer reviewed.

(C) Author(s) (or their employer(s)) 2019. No commercial re-use. See rights and permissions. Published by BMJ.

\section{Check for updates}

To cite Bergeron $M$, West $L R$, Stamatakis $E$. Br J Sports Med 2019;53:985.

Accepted 11 June 2019

Br J Sports Med 2019;53:985

doi:10.1136/bjsports-2019-101164 